\title{
RETRATOS DO BRASIL E O DIÁLOGO COM O DIREITO ADMINISTRATIVO
}

\author{
Edimur Ferreira de Faria* \\ Marcos Pereira Anjo Coutinho**
}

\begin{abstract}
RESUMO: A investigação, alicerçada no pensamento tópico e problemático, que sobrepuja a ideia de sistema fechado e da estrita metodologia dedutiva ou indutiva, questiona a existência de dimensões normativas da governança e do planejamento na ordem jurídica nacional, tendo como objetivo o diálogo entre obras retratistas e o Direito Administrativo brasileiro, estabelecendo-se a conexão entre o enfrentamento dos ciclos de pobreza, os objetivos da República e o papel da Administração Pública, promovendo o debate sobre a figura atual do Estado diante dos ciclos deletérios mantenedores da faoriana "viagem redonda" brasileira, em obstáculo à eficácia social dos direitos fundamentais.
\end{abstract}

PALAVRAS-CHAVE: Retratos; Brasil; Interdisciplinaridade; Objetivos; República; Direito Administrativo.

\section{PORTRAITS OF BRAZIL IN ADMINISTRATIVE LAW}

ABSTRACT: The research, based on topical and problematic thinking, that surpasses the idea of a closed system and the strict deductive or inductive methodology, questions the existence of normative dimensions of governance and planning in the juridical order, aiming at the dialogue between portraits and the Administrative Law, establishing the connection between the confrontation of the cycles of poverty, the objectives of the Republic and the role of Public Administration, promoting the debate about the current state figure in the face of the deleterious cycles that maintain the "round trip", as an obstacle to the social effectiveness of fundamental rights.

KEY WORDS: Portraits of Brazil; Interdisciplinarity; Functions; Republic; Administrative law

\footnotetext{
* Doutor e mestre em Direito Administrativo pela Universidade Federal de Minas Gerais, professor no Curso de Graduação e no Programa de Pós-Graduação em Direito da Pontifícia Universidade Católica de Minas Gerais, exDiretor da Faculdade Mineira de Direito da PUC Minas, ex-Diretor da Escola de Contas e Capacitação do Tribunal de Contas do Estado de Minas Gerais, ex-Presidente do Instituto Mineiro de Direito Administrativo. Endereço eletrônico: edimurfaria@hotmail.com.

** Especialista em Controle da Administração Pública pela Universidade Gama Filho. Especialista em Tutela de Interesses Difusos e Coletivos pela Unama. Mestre em Direito Público pela Pontifícia Universidade Católica de Minas Gerais - PUC-Minas. Promotor de justiça do Ministério Público de Minas Gerais. Assessor Especial do Procurador-Geral de Justiça de Minas Gerais junto à Coordenadoria de Controle de Constitucionalidade da Procuradoria-Geral de Justiça. Endereço eletrônico: marcos.anjocoutinho@gmail.com.
} 


\section{INTRODUÇÃO}

A ideia de permeabilidade do sistema jurídico não é nova, sendo aceita por positivistas como Hans Kelsen e H. L. A. Hart, bem como pelo universo geral de não positivistas, embora, ainda hoje, encontre obstáculos na observação do funcionamento patrimonialista e burocrático de Administrações públicas brasileiras.

As peculiaridades do Brasil conferem, então, impulso aos debates que identificam, nos atributos e matizes nacionais, elementos capazes de influenciar a construção de argumento jurídico harmonioso com os traços que nos são característicos, na busca do contínuo aperfeiçoamento administrativo e da realização dos direitos fundamentais.

O cotejo jurídico entre as normas da Administração Pública e os objetivos constitucionais da República brasileira, nesse contexto, permite o diálogo entre diferentes sistemas, como a Antropologia, Sociologia, Economia, Ciência da administração e História.

Os retratos do Brasil, entendidos como obras artísticas, antropológicas, históricas, econômicas e sociológicas que versam sobre a formação e as características brasileiras, surgem nesta pesquisa como matéria relevante na discussão dos contornos do Estado brasileiro contemporâneo, capazes de auxiliar o desvelamento de aspectos nacionais a merecerem especial enfoque para a consecução satisfatória dos objetivos constitucionais normatizados em 1988.

Por meio dos retratos, é possível detectar, mais do que simples fatos sociais, históricos ou antropológicos isolados, a existência de ciclos deletérios, aqui examinados sob a ótica dos poverty cycles, nascidos das situações deficitárias no meio comunitário e/ou estatal, como o patrimonialismo, a falta de saneamento básico, o ensino público fundamental de má qualidade e os loteamentos clandestinos, que, em retroalimentação, também fomentam a continuidade do quadro complexo de ofensas a direitos fundamentais.

Questiona-se, dessa forma, se a pobreza tem repercussão no campo jurídico administrativo brasileiro e, em caso positivo, quais seriam os caminhos para que o Estado brasileiro, despido de qualquer traço de populismo, possa melhor contribuir, no Direito Administrativo, para o enfrentamento estratégico dos ciclos provenientes das ofensas ao piso vital, estimulando-se a ruptura da faoriana viagem redonda nacional.

A metodologia aberta deste trabalho, como será examinado em sequência, consistiu essencialmente na revisão bibliográfica das obras retratistas de Raymundo Faoro (Os donos do poder), Roberto DaMatta (O que faz o brasil, Brasil), Alberto Carlos Almeida (A cabeça do brasileiro), de Victor Nunes Leal (Coronelismo, enxada e voto) e de Willi Bole 
(Grandesertão.br), na doutrina administrativa constitucional brasileira e estrangeira, de modo a fixar a coerência das ideias, a concretude do tema e a sua relevância teórica.

\section{INTERDISCIPLINARIDADE E AS METODOLOGIAS ABERTAS DA PESQUISA}

Os retratos do Brasil, inseridos na esfera jurídica, impõem necessariamente o diálogo da ciência jurídica com outros conhecimentos.

Há o reconhecimento de que a identificação dos traços da nação brasileira, na formação e interpretação do constitucionalismo pátrio, é ponto sensível da pesquisa sobre o Direito Administrativo e suas repercussões na adequada prestação da atividade estatal e na consequente maximização da eficácia social dos direitos fundamentais.

Busca-se, nessa linha, trazer argumentos que respondam, com alicerces teóricos compatíveis, as perguntas centrais relativas à repercussão jurídica do fenômeno da pobreza e os caminhos constitucionais e administrativos porventura viáveis para o melhor enfrentamento jurídico, em cenário de crise em larga escala: crise da democracia representativa; crise institucional e política brasileira; crise dos modelos econômicos e da globalização; crise social, com o avanço da pobreza (SCHWARTZMAN, 2007); e, no campo acadêmico, de continuada crise da razão.

A crise da razão é aqui compreendida como o reconhecimento do caráter incompleto e relativo das respostas advindas da problematização formulada com lastro nas metodologias de produção do conhecimento científico.

Nesse cenário de desconfiança das fórmulas teóricas puras, optou-se por construir argumentação fulcrada nas particularidades do constitucionalismo brasileiro, em "narrativa construída no interior de seus paradoxos” (BARACHO JÚNIOR, 2009, p. 162).

Sem refutar a importância do dogmatismo jurídico, saber quem somos, como estamos e o que buscamos como nação são reflexões primárias indissociáveis do estudo dos nossos direitos fundamentais e das conflitualidades hermenêuticas (GARCIA, 2015, p. 561 e 572).

Encampa-se o paradigma de que a ciência é um fenômeno político e social também, a romper com os modelos ideais, impulsionando a pesquisa complexa, o que é acentuado nas ciências sociais aplicadas.

Nesse sentido, confere-se relevo à dimensão normativa da Constituição, sem abandonar o enfoque da sua dimensão real na formação da ordem jurídica, o que no Brasil é medida útil para o exame dos paradoxos nacionais: o Estado Democrático de Direito no eterno País do futuro, em que "os donos do poder" (FAORO, 2012) consolidam a "insinceridade normativa”. 


\title{
3 RETRATOS DO BRASIL, OBJETIVOS CONSTITUCIONAIS DA REPÚBLICA E O ENFRENTAMENTO DO POVERTY CYCLE
}

Os retratos do Brasil viabilizam meios de identificação de ciclos deletérios do País, entendidos como fenômenos sociais, econômicos ou políticos que inibem o funcionamento estatal idealizado no texto normativo. O diálogo com o Direito Administrativo, como será visto, possibilita uma abordagem qualificada dos problemas nacionais e o incentivo à eficácia social de normas fundamentais da República.

Nesse contexto, a interpretação brasiliana de Raymundo Faoro, na obra Os donos do poder, reforça o dever de precaução constitucional para que o Estado, através da sua dimensão administrativa e burocrática, não sirva de meio ou instrumento para a continuidade de privilégios dos estamentos, em mecanismo de retroalimentação nociva que perdura até os dias atuais, na denominada "viagem redonda".

O patrimonialismo, segundo Faoro, é patologia presente em fases e períodos brasileiros diversos até os dias atuais, resistindo ao capitalismo e à ideologia liberal, inclusive, fomentando um capitalismo peculiar, baseado no Estado burocrático estamental, com os políticos atuando em interesses próprios, sem a percepção do povo:

\begin{abstract}
A obra Os Donos do Poder - Formação do Patronato Político Brasileiro, de Raymundo Faoro, traz como tema central uma explicação para as mazelas do Estado e da nação brasileiros: a estrutura de poder patrimonialista estamental plasmada historicamente pelo Estado português, posteriormente congelada, transplantada para a colônia americana, reforçada pela transmigração da Corte lusa no início do século XIX e transformada em padrão a partir do qual se organizaram a Independência, o Império e a República no Brasil.

Uma imutabilidade histórica, que se constitui através de arranjos intimamente relacionados nos campos econômico e sociopolítico. No primeiro, prevalece o capitalismo politicamente orientado. O Estado não assume o papel de fiador e mantenedor de uma ordem jurídica impessoal e universal [...] (CAMPANTE, 2003, p. 153).
\end{abstract}

Por sua vez, o trabalho multiangular do antropólogo Roberto DaMatta guarda relevância para esta pesquisa ao abordar as perturbações e os paradoxos entre o "mundo da casa” e o “mundo da rua”, bem como as diferenças entre pessoas e a coletividade, as primeiras carregadas de direitos, valores familiares e tradicionais, descoladas do agrupamento de indivíduos, essencialmente desarticulado, representando um dos traços das nossas disfuncionalidades comunitárias (DaMATTA, 1997, p. 31-32).

Extrai-se, dessa visão, que os "modos de navegação social” 1 exteriorizam os contrastes

\footnotetext{
1 “[...] o dilema brasileiro residia numa trágica oscilação entre um esqueleto nacional feito de leis universais cujo sujeito era o indivíduo e situações onde cada qual se salvava e se despachava como podia, utilizando para isso o seu sistema de relações pessoais. Havia, assim, nessa colocação, um verdadeiro combate entre leis que devem
} 
dos diferentes Brasis, retroalimentando, por via obliqua, o desajuste da máquina pública:

[...] Como é que se faz diante de um requerimento que está sempre errado? Ou diante de um prazo que já se esgotou e conduz a uma multa automática que não foi divulgada de modo apropriado pela autoridade pública? Ou de uma taxação injusta e abusiva que o Governo novamente decidiu instituir de modo drástico e sem consulta? [...] entre o "pode" e o "não pode" escolhemos, de modo chocantemente antilógico, mas singularmente brasileiro, a junção do "pode" com o não pode”. Pois bem, é essa junção que produz todos os tipos de "jeitinhos" e arranjos que fazem com que possamos operar um sistema legal que quase sempre nada tem a ver a realidade social (DaMATTA, 1997, p. 99-101).

A advertência de que o Direito nacional deve estancar a promoção dos “jeitinhos”, que

podem ser enxergados na dimensão estéril da insinceridade normativa, intimamente ligada à fraqueza dos laços comunitários e ao patrimonialismo, é leitura que conecta a presente pesquisa a Roberto DaMatta².

Noutro ângulo, a obra Coronelismo, enxada e voto, de Victor Nunes Leal, desenvolve a concepção profunda de coronelismo e dos fenômenos inerentes aos poderes políticos e econômicos locais. Até essa obra, era inexistente a compreensão do verdadeiro sistema deletério gerado por conta dessa realidade brasileira.

Desnuda-se que o Estado tinha controle sobre o "coronel” ao permitir toda sorte de domínio e abusos, eleitorais ou não, dos chefes municipais, o que lhe era útil no simbólico processo democrático regional e nacional, em que os políticos obtinham votos consideráveis graças ao sistema viciado. A propósito Leal assevera:

A essência, portanto, do compromisso 'coronelista' - salvo situações especiais que não constituem regra - consiste no seguinte: da parte dos chefes locais, incondicional apoio aos candidatos do oficialismo nas eleições estaduais e federais; da parte da situação estadual, carta branca ao chefe local governista (de preferência o líder da facção local majoritária) em todos os assuntos relativos ao

valer para todos e relações que evidentemente só podem funcionar para quem as tem. O resultado é um sistema
social dividido e até mesmo equilibrado entre duas unidades sociais básicas: o indivíduo (o sujeito das leis
universais que modernizam a sociedade) e a pessoa (o sujeito das relações sociais, que conduz ao polo tradicional
do sistema). Entre os dois, o coração dos brasileiros balança. E no meio dos dois, a malandragem, o “jeitinho” e o
famoso e antipático “sabe com quem está falando?” seriam modos de enfrentar essas contradições e paradoxos de
modo tipicamente brasileiro. Ou seja: fazendo uma mediação também pessoal entre a lei, a situações onde ela
deveria aplicar-se e as pessoas nela implicadas, de tal sorte que nada se modifique, apenas ficando a lei um pouco
desmoralizada mas, como ela é insensível e não é gente como nós, todo mundo fica, como se diz, numa boa e a
vida retorna ao seu normal.” (DaMATTA, 1997, p. 97-98).
2 “Há críticas, e muitas, à contribuição de Roberto DaMatta à antropologia. A mais raivosa de todas é de Jessé de
Souza no livro O malandro e o protestante. Mas, tal como diz o ditado que “cão que ladra não morde”, ela é tão
raivosa quanto inofensiva. Jessé simplesmente nega que DaMatta esteja correto sem apresentar evidência empírica
alguma que sustente sua tese. Por exemplo, para Jessé, a corrupção que atingiu o ex-primeiro ministro alemão
Helmut Kohl mostra que a corrupção não é exclusividade do Brasil. Concordamos com ele, porém, qual o nível
de corrupção de Alemanha e Brasil? O escândalo que atingiu Kohl não se compara com escândalos que atingem
inúmeras prefeituras pelo Brasil afora. Ao contrário de Jessé, os resultados de nossa pesquisa fazem uma crítica
moderada, mas consistente, à interpretação damattiana do Brasil. [...] Mas é uma crítica generosa porque - se
estiver correta - coloca a obra de DaMatta em outro patamar: ele não estaria falando especificamente do Brasil,
mas sim da cultura de qualquer sociedade cuja escolaridade geral é muito baixa” (ALMEIDA, 2007, p. 275-276). 
município, inclusive na nomeação de funcionários estaduais do lugar (LEAL, 2014, p. 67-68).

Victor Nunes Leal reconhece que o sistema coronelista foi atacado a partir da revolução de 1930, com a melhoria da condição social, do desenvolvimento da economia industrial e da urbanização, mas sugere, mesmo afirmando buscar apenas a compreensão do modelo sem soluções de correção prontas, que o golpe de morte ao coronelismo apenas será materializado quando seu “círculo vicioso” for efetivamente dinamitado no país, a indicar operação complexa, mediante a tomada de ações diferenciadas; econômicas, sociais, políticas e jurídicas.

A ideia de ciclos de atraso nacional que se retroalimentam das situações originadas dos déficits brasileiros, nos mais variados espectros, é ponto relevante para o desenvolvimento do raciocínio ora estabelecido.

Finalmente, como derradeira obra retratista examinada nesta breve pesquisa, o livro Grandesertão.br, de Willi Bolle, traz densa imersão no romance de João Guimarães Rosa, que apresenta o diálogo de Riobaldo com um interlocutor não determinado, descrevendo-se as idas e vindas de sua travessia de vida, como filho de fazendeiro rico, proprietário de terra, jagunço e líder de bando a vingar a morte Joca Ramiro, pai de Diadorim. Riobaldo, nesse sentido, tem revelada sua dupla posição social.

Os estratagemas de dissimulação no julgamento de Zé Bebelo ocorrido na Fazenda Sempre-Verde representam, alegoricamente, o funcionamento das estruturas de poder no Brasil, expostas no romance por meio da falsa expectativa da paz no sertão com a vitória sobre o adversário; do “faz-de-conta de que a guerra no sertão é uma forma de rebeldia contra as forças do Governo repressor"; e da "ilusão de que os chefes se pautam pelo julgamento de seus subordinados.” (BOLLE, 2004, p. 135-137).

O exame de Grande Sertão: Veredas permite a leitura do discurso mitificador e dissimulador das estruturas de dominação existentes na nação brasileira:

Seu romance é carregado de elementos míticos, porque só assim é possível reproduzir o discurso essencialmente mitificador e dissimulador das estruturas de dominação - reproduzir, para que o comentário do narrador possa revelar como a violência institucionalizada articula o seu discurso (BOLLE, 2004, p. 139).

Willi Bolle ainda realiza a leitura do pacto faustiano ocorrido nas Veredas-Mortas como símbolo de um falso contrato social, com lastro na teoria política de Rousseau. O bando de jagunços rasos, a "horda primitiva”, fixa-se como o coletivo humano anterior ao próprio contrato social. 
Assim, o acordo entre os proprietários de terra, chefes da jagunçagem e jagunços seria a alegoria do modelo inverídico do contrato social legitimador do poder não democrático; falso porque na aparência se refere, abstratamente, ao acordo entre iguais, mas, em verdade, não revela a existência de qualquer ajuste entre povo e representantes de seus interesses reais. Não há vestígio de soberania popular.

Nessa linha de raciocínio, os objetivos constitucionais da República brasileira, sob a dimensão normativa do art. $3^{\circ}$ da Constituição de 1988, orientam e vinculam a governança e a atuação planejada do Estado.

E, neste ponto, ganha relevo o alerta já formulado há décadas pelos retratos do Brasil: as ambiguidades e dissimulações inerentes à repartição do poder entre os chefes e os estamentos nacionais, em simulacro democrático rousseauniano, não podem ser ignoradas pelos operadores do Direito no exame da concretização jurídica da Constituição.

Como trilhar as metas constitucionalmente estabelecidas, num ambiente patrimonialista exacerbado, revelador da função hipertroficamente simbólica do texto normativo (NEVES, 2011), que discrepa da eficácia social do Direito brasileiro? Os retratos do Brasil viabilizam, assim, a formulação de crítica interna com enfoque nos contornos nacionais, permitindo o debate sobre a adequação de nossas construções e importações teóricas, nossos silêncios legislativos, simulacros jurídicos e ambiguidades, tornando a ciência jurídica, ao menos, fonte transparente de ponderação das vicissitudes nacionais. O ato de "tapar o sol com a peneira” por meio do Direito fica enfraquecido, o que, por si só, já representa contribuição democrática à efetividade normativa.

Descortina-se um Estado prestacional abstratamente desenhado após 1988 em que os serviços públicos essenciais de educação, saúde, segurança pública e tantos outros funcionam mal. Em verdade, havendo disponibilidade de recursos financeiros pessoais, o primeiro passo do cidadão é distanciar-se ao máximo desses serviços prestados pelo poder público, seja com planos de saúde, escolas particulares, contratos de seguro, segurança privada etc., em contradição com o texto da Constituição vigente.

Os objetivos constitucionais da República brasileira formalizam a natureza planejadora da Constituição, indicativa da importância de um Direito Administrativo sensível aos pontos de partida do sistema. Essa leitura administrativa do texto constitucional adquire caráter estratégico, por força do próprio formato prestacional do Estado brasileiro.

Lado outro, o ataque aos ciclos de pobreza enseja também o enfoque administrativo, por meio da realização do planejamento estatal e da crítica ao patrimonialismo. Revela-se dever 
jurídico prioritário do Estado, porquanto decorrente de objetivos da República, residindo aí a importância estratégica do Direito Administrativo.

Não se desconhece que a chaga populista, efervescente no Brasil, torna ainda mais delicada a abordagem jurídica da pobreza, que é assunto complexo e resistente ao tempo.

Quando se fala em pobreza, a ideia que se pode ter é a da pequena relevância, no campo jurídico, desse fenômeno. Pobreza teria alguma repercussão restrita à seguridade social e, mais especificamente, à assistência social (COUTINHO, 2017).

Modelos antigos de visão de mundo, fortalecidos pela atual crise de democracia representativa, em que os políticos eleitos, com frequência, distanciam-se das expectativas mais elementares, contribuem para o fortalecimento comunitário dessas distorções sobre o tema.

A realidade constitucional brasileira, entretanto, exibe a concretude normativa da matéria, assim definida pelo constitucionalista José Afonso da Silva:

A pobreza é o estado de quem não tem o necessário para a vida, de quem vive com escassez; [...] consiste, assim, na falta de renda e recursos suficientes para 0 sustento, na fome e na desnutrição, más condições de saúde, limitado acesso à educação e na maior incidência de doenças e mortalidade, especialmente mortalidade infantil. [...] Pois bem, erradicar esse estado é o que constitui o objetivo fundamental da República aqui analisado. [...] Em verdade, também a erradicação da pobreza e da marginalização é um modo de se construir aquela sociedade livre, justa e solidária, objetivo fundamental consignado no inciso I do artigo em comentário (SILVA, 2006, p. 47-48).

São decisivos, portanto, o diagnóstico e a compreensão dos inúmeros ciclos de pobreza, “caracterizados como a retroalimentação originada do próprio ambiente deficitário, sendo simultaneamente efeito e causa”, representativos de “[...] fenômenos sociais, econômicos e políticos que auxiliam a manutenção de uma determinada situação de carência. Apresentamse, assim, como nocivos elementos estabilizadores de um quadro de pobreza, não dinamitáveis sem uma intervenção externa” (COUTINHO, 2015, p. 152).

Conforme se depreende das colocações desenvolvidas, um dos ciclos de pobreza fixase na estrutura patrimonialista do Estado brasileiro, intimamente conectada, por sua vez, com a higidez da Administração Pública brasileira.

Adota-se concepção elástica de patrimonialismo, onde o clientelismo, o fisiologismo, o assistencialismo, mandonismo, o filhotismo germinam no campo fértil da pobreza. Mas, corroboram também a sua manutenção, pertencendo a eles a paternidade de entraves sociais, nessa complexa ciranda de ofensas a direitos do homem.

Ao Direito importa discutir a matéria, em obediência aos pontos de partida do sistema brasileiro, o que é, em tese, de interesse jurídico relativo para outras potências do Direito 
Constitucional, reforçando-se, assim, a convicção das particularidades dos retratos do Brasil. Abre-se o horizonte para pensar a Constituição sob prisma nacional.

O patrimonialismo, enquanto ciclo de pobreza, é causa e efeito da permanência do insatisfatório funcionamento da máquina estatal, escancarando, por meio da desgovernança, as portas para o empreguismo e a corrupção. Nesse sentido expressa Almeida:

Patrimonialismo e corrupção são idéias afins, e isso significa que quanto mais alguém acha correto e defende valores patrimonialistas, mais tenderá a ser tolerante com a corrupção e práticas correlatas. Nesse sentido, os dados da PESB permitem concluir que essa tolerância é realmente maior entre aqueles de escolaridade mais baixa; que a população do Nordeste convive melhor com a corrupção do que os habitantes da região Sul... [...] Que tipo de pressão sofre um político eleito em grande parte por pessoas que formam aqueles $17 \%$ que consideram correto usar um cargo público em seu próprio benefício? (ALMEIDA, 2007, p. 109).

Diante da leitura administrativa dos objetivos da Constituição é possível afirmar que Direito Administrativo tem função a cumprir nos esforços estatais destinados ao enfraquecimento de específico ciclo de pobreza, ao favorecer a ruptura do paradigma patrimonialista na Administração Pública, e, consequentemente, auxiliar o satisfatório desfecho da distópica “viagem redonda” de Raymundo Faoro.

\section{DIREITO ADMINISTRATIVO CONTEMPORÂNEO}

Este item será bastante sintético em virtude da limitação de páginas para atender exigências do CONPEDI. Para facilitar a sua compreensão e na tentativa de torna-lo didático será dividido em subitens.

\subsection{ORIGEM E EVOLUÇÃO DO DiREITO AdMINISTRATIVO}

O Direito Administrativo, ramo de Direito Público, ainda, relativamente novo, teve origem no Direito Frances, após a instituição do Estado de Direito com a tripartição das funções especializadas ou poderes do Estado: legislativa, executiva e judiciária. Essas funções, durante mais de dois séculos, foram compreendidas como sendo poderes do Estado: Poder Legislativo, Poder Executivo e Poder Judiciário, baseado na teoria da tripartição de poderes formulada por Montesquieu, na renomada obra denominada “Espírito das Leis”. A ideia dessa especialização surgiu com Aristóteles, em oposição à centralização de poderes nas mãos do monarca soberano, durante o Estado Absolutista. Depois de Aristóteles surgiu Jhon Lock, que deu um paço à frente. O jusfilósofo sustentava a necessidade de se criar um órgão que cuidasse da edição das leis. O qual ele denominou de Assembleia, que seria convocada para editar leis de caráter permanente. Depois de editadas as leis ou a lei, para qual função foi convocada, a Assembleia seria dissolvida. Para aplicar as leis, seria criado um órgão com função executiva, permanente. Por 
fim, o órgão encarregado de dirimir os conflitos relativos a aplicação das leis nos casos concretos.

Nas últimas décadas, a doutrina vem se desenvolvendo em torno da ideia de que não é correta a teoria da tripartição de poderes, considerando, principalmente, que o poder emana do povo que o exercerá diretamente ou por meio de representantes eleitos (art. $1^{\mathrm{o}}$, da Constituição da República de 1988). Então, se o poder é uno e indivisível, seria impossível a sua tripartição. Daí, o entendimento, de que se trata de divisão de funções e não de poderes.

Incialmente, o Direito Administrativo foi considerado Direito da Administração Pública. Tanto que os Estados Unidos, baseados nos três Poderes ou funções especializadas, refutaram a criação do ramo Direito Administrativo, sob o argumento de que a Administração Pública deveria submeter-se aos mesmos direitos aplicáveis a todos. Da mesma forma, entenderam extravagante a ideia de adoção de jurisdição administrativa (contencioso administrativo) instituído na França nos primórdios do Estado de Direito, para julgar as questões entre pessoas de Direito Público.

Numa segunda fase, o Direito Administrativo deixa de ser considerado Direito da Administração Pública para ser um direito meio de defesa dos administrados em defesa dos seus direitos básicos constitucionalmente garantidos, principalmente na vigência do paradigma do Estado do Bem-estar social.

Na vigência do paradigma do Estado Democrático de Direito, a criação e a efetivação do Direito, em especial o Direito Administrativo, passa a ser construído, em tese, com a efetiva participação social, por meio de permanente diálogo do Estado com a sociedade, na busca de solução para a sociedade e para o País, superando assim, a gestão patrimonialista, que como visto, esteve presente no Brasil desde o início de sua colonização.

O Estado Democrático de Direito brasileiro, nos termos e condições estabelecidos pela Constituição da República de 1988 é recheado de normas e de preceitos destinados ao desenvolvimento e ao bem estar social. Nesse sentido, a título de exemplos cintam-se os seguintes artigos da Constituição da República: art. $3^{\circ}$ cuida dos objetivos fundamentais da República Federativa do Brasil. São eles: construir uma sociedade livre, justa e solidária (inciso I); garantir o desenvolvimento nacional (inciso II); erradicar a pobreza e a marginalização e reduzir as desigualdades sociais e regionais (inciso III); promover o bem de todos, sem preconceitos de origem, raça, sexo, cor, idade e quaisquer outras formas de discriminação (inciso IV). $\mathrm{O}$ art. $5^{\circ}$ arrola os direitos fundamentais, os art.163 e 164 dispõem sobre finanças públicas e os art. 165 a 169 imprimem orientações básicas sobre orçamentos públicos. 
A regulamentação e disciplinamento desses direitos condicionam-se a edição de leis específicas de iniciativa do Legislativo ou do Executivo (Ambos devem estar antenados, afinados e solidários com o firme propósito de cumprir a Constituição. O Judiciário só deve atuar nos casos de omissão ou descumprimento pelo Legislativo ou o Executivo ou por ambos de seus deveres constitucionais) e de adequada e efetiva gestão pública dialógica.

A boa e eficiente gestão pública depende de planejamento, orçamento e governança para a obtenção dos resultados materiais, financeiros e sociais esperados na vigência do Estado Democrático de Direito.

\subsection{O DIREITO ADMINISTRATIVO BRASILEIRO NA CONTEMPORANEIDADE}

O Direito Administrativo que antes foi considerado Direito da Administração Pública, posteriormente Direito de defesa dos interesses dos administrados, passa, no Brasil, com a promulgação da Constituição da República de 1988, a ser Direito construído pela Administração com a participação da sociedade, por meio de procedimento dialógico, observados os parâmetros constitucionais, com a finalidade precípua de efetivar os direitos fundamentais garantidos constitucionalmente.

A participação social faz-se, no plano legislativo, por meio de iniciativa de lei, de plebiscito e de referendo, no plano administrativo, por meio de orçamento participativo, audiência pública, consulta pública, entre outras, previstas em leis, como por exemplo a Lei n. 8.666, de 21.06.1993 (lei geral sobre licitações e contratações públicas). O $\S 1^{\text {o }}$, do art. 41 estabelece que qualquer cidadão é parte legítima para impugnar o Edital de licitação que apresentar irregularidade em face da lei. Em outros dispositivos, a mesma lei franquia a participação de cidadãos nas reuniões da Comissão de Licitação, desde que não tumultuem os trabalhos objeto da reunião, estabelece que qualquer cidadão é parte legitima para denunciar à Administração que os preços registrados estão acima dos praticados no mercado e, por fim, legitima os cidadãos para representar perante o respectivo Tribunal de Contas, irregularidades em licitações, em contratações e na execução de contratos.

A Lei n. 8.987, de 13.12.1995 garante ao usuário o direito de reclamar perante o concessionário de serviço público e/ou poder concedente, falha ou irregularidade na prestação do serviço concedido.

A Constituição da República e legislação infraconstitucional preveem a criação de diversos Conselhos Sociais paritários obrigatórios. Entre os quais, Conselho de Saúde, Conselho Tutelar, Conselho do Meio Ambiente, Conselho do Idoso, Conselho de Previdência Social. 
Esses são alguns exemplos de participação social na positivação do direito, na formulação das políticas públicas e no controle da Administração Pública. Mas para que a participação social se efetive como prevê o ordenamento jurídico pátrio, são necessários orçamento, planejamento, gestão, governança, vontade popular e controle, como dito acima. Nos subitens seguintes serão examinados cada um desses tópicos.

\subsubsection{Orçamento Público e Planejamento}

Em qualquer atividade humana, o orçamento e planejamento são necessários, na família, na empresa privada e nas atividades profissionais liberais, por exemplo. $\mathrm{Na}$ Administração Pública o orçamento e o planejamento são obrigatórios.

O art. 165, caput, da Constituição da República prescreve que leis de iniciativa do chefe do Executivo disporão sobre plano plurianual, as diretrizes orçamentárias e os orçamentos anuais.

O plano plurianual - PPA, concebido e disciplinado por meio de lei específica de cada ente da Federação é de natureza orçamentária e planejamento. Dada a sua importância para a realização das políticas públicas, a sociedade ou segmento dela deve ser convocada para participar ativamente de sua elaboração, nos moldes e parâmetros da administração dialógica.

A lei instituidora do plano plurianual deve estabelecer as diretrizes, objetivos e metas a serem cumpridas pala Administração Pública nos quatro planos de governo, para as despesas de capital e para as relativas aos programas de duração continuada (§ $1^{\circ}$, art. 165).

De acordo com a legislação vigente, o plano plurianual deve ter a duração mínima de 4 (quatro) anos. Ele deve ser elaborado pelo Executivo e aprovado pelo Legislativo, até ao final do primeiro ano do mandato do Chefe do Executivo, entrando em vigor em primeiro de janeiro do segundo ano do mandato com vigência até trinta e um de dezembro do primeiro ano do mandato seguinte. Dessa forma, o empossado no cargo de Chefe do Executivo, administra no primeiro ando do seu mandato, observando o plano plurianual concebido pelo seu antecessor, ou por ele próprio, no caso de reeleição.

A mensuração das receitas e das despesas com cada programa ou projeto, previstos no plano plurianual é efetivada por meio da lei de orçamento anual, LOA, que se condiciona à lei de diretriz orçamentária - LDO. Essa lei, como o próprio nome sugere, estabelece as diretrizes para a elaboração da lei orçamentária anual. Ela deve contemplar o equilíbrio entre receitas e despesas, as metas e prioridades da Administração Pública, incluir as despesas de capital para o exercício financeiro subsequente, normas sobre o controle de custos e de avaliação dos resultados e sobre orientação para a elaboração da lei orçamentária anual. Deve, ainda, dispor 
sobre as alterações das leis tributárias e estabelecer a política de aplicação das agências financeiras oficias de fomento, entre outras medidas, que servem de subsídios para a lei de orçamento anual - LOA. A LDO, dada a sua importância na intermediação entre a lei do plano plurianual e a lei de orçamento anual, deve ser votada e sancionada antes do recesso do Legislativo do meio do ano. Isso porque o projeto de lei de orçamento anual tem início no Executivo, em julho e no final de agosto deve ser encaminhado ao Legislativo para discussão, apresentação de emendas parlamentares individuais e de bancadas e votação e sanção até o final de dezembro para entrar em vigor em primeiro de janeiro do ano subsequente. O conteúdo básico da lei de orçamento anual compreende três orçamentos conforme prescreve o art. 165, § $5^{\circ}$, da Constituição, assim redigido:

\section{§ $5^{\circ}$ A lei orçamentária anual compreenderá:}

I - o orçamento fiscal referente aos Poderes da União, seus fundos, órgãos e entidades da administração direta e indireta, inclusive fundações instituídas e mantidas pelo Poder Público;

II - o orçamento de investimento das empresas em que a União, direta ou indiretamente, detenha a maioria do capital social com direito a voto;

III - o orçamento da seguridade social, abrangendo todas as entidades e órgãos a ela vinculados, da administração direta ou indireta, bem como os fundos e fundações instituídos e mantidos pelo Poder Público.

A lei em referência, observa princípios, como o da universalidade, o da anualidade e o da unidade.

O orçamento anual, durante a sua execução, pode sofrer alterações com vistas a adequar as políticas públicas às reais necessidades e à efetiva disponibilidade financeira, considerando que o Estado não pode realizar despesas além das respectivas receitas.

\subsubsection{Governança no setor público}

As leis específicas sobre orçamento público e planejamento, examinadas acima não são suficientes para se evitar integralmente, o ranço da cultura da administração patrimonialista. Para evita-la de vez, é necessária gestão transparente com governança pública participativa.

A governança corporativa surgiu nas empresas privadas e se aprimorou com as corporações contemporâneas que separam a atividade de controle da atividade de gestão. Essa bipartição de funções decorre, principalmente da necessidade dos acionistas, geralmente, distantes da gestão da companhia terem meio de controle de modo a possibilitar verificar se os administradores estão adotando políticas de gestão compatíveis com os seus interesses.

Uma das medidas adotadas nas corporações de médio e grande porte foi a substituição do acionista controlador por administrador profissional com conhecimento no ramo da empresa, dotado de comprovada competência gerencial, contratado para o cargo de presidente o de administrador da companhia. Ferreira (2014) pontua que “a substituição do acionista 
controlador pelo administrador trouxe maior profissionalismo à gestão, embora exista a dificuldade de alinhamento de interesses entre todas as partes envolvidas”.

Além da substituição, acima referida, a governança corporativa tem por escopo compatibilizar as relações entre a gestão, os conselhos de administração e fiscal, os acionistas, os funcionários em todos os níveis da empresa e outros interessados, tendo sempre em vista a produtividade, a produção e a lucratividade da corporação, em ambiente de ética e transparência e observância do ordenamento jurídico.

A governança pública, em processo de amadurecimento, recebe influência da governança corporativa, com as particularidades próprias do setor público. O Direito Alemão é um dos principais percursores da governança pública. Em palestra sobre o tema, Leo Kissler e Francisco G. Heidemann formulam a seguinte pergunta: O que é governança pública? Eles próprios iniciam a resposta com o seguinte texto:

No debate atual sobre a continuidade da modernização do setor público alemão, a governança tornou-se um conceito-chave, que todos utilizam sem saber exatamente o que é. Seu significado original continha um entendimento associado ao debate político-desenvolvimentista, no qual o termo era usado para referir-se a políticas de desenvolvimento que se orientavam por determinados pressupostos sobre elementos estruturais como - gestão, responsabilidades, transparência e legalidade do setor público - considerados necessários ao desenvolvimento de todas as sociedades (pelo menos de acordo com os modelos idealizados por organizações internacionais como a Organização das Nações Unidas [ONU] ou a Organization for European Cooperation and Development [OECD]) (KISSLER; HEIDEMANN, 2006).

Os principais motivos que levaram a Administração Pública a adotar os procedimentos de governança são, a globalização econômica e política, a pressão social por melhoria das políticas públicas. Essas duas realidades, entre outras, trouxeram repercussão direta ou indireta nos gastos públicos, fatos que levaram a Administração a se organizar e se controlar com a finalidade de superar as suas dificuldades econômicas. Para isso, tornou-se imperiosa a adoção de gestão aparelhada e adequada semelhante à adotada nas corporações privadas.

A propósito do tema os citados autores alemães asseveram

O Estado deixa de ser uma instituição que se diferencia de forma clara e distinta do mercado e da sociedade, como acontecia no caso do governo tradicional. Estado, mercado, redes sociais e comunidades constituem mecanismos institucionais de regulamentação, que se articulam em diferentes composições ou arranjos. Por isso, a governança prescreve uma lógica de gestão tanto para uma organização quanto para um setor e é usada como conceito-chave para vários tipos de atividades coordenadas. Na verdade, determinadas formas de governança ainda são típicas para certos campos de atuação, como, por exemplo, a hierarquia para o Estado e o mercado para a iniciativa privada. Mas estudos empíricos demonstram que, no ínterim, surgiram arranjos institucionais nos quais transparece um mix de governança. Esse mix caracteriza-se por estruturas mistas, ou híbridas, em que atuam diferentes mecanismos de gestão (controle hierárquico, 
concorrência, confiança e solidariedade). Seguindo essa tese, as formas coletivas de atuação na sociedade podem ser melhor compreendidas dessa forma do que pelo conceito tradicional de Estado ou pelo conceito de sistema de governo. Para essa perspectiva, é decisiva a transição do Estado gestor (hierárquico), com ingerência na sociedade, para o Estado cooperativo, que atua em conjunto com a sociedade e as organizações empresariais, por meio de parcerias estratégicas.

O Estado Brasileiro, desde a profunda reforma implementada no Governo do Fernando Henrique Cardoso, deixando de ser Estado empresário empregador e provedor, para se tornar Estado regulador e fiscalizador das atividades relativas a políticas públicas prestadas pela iniciativa privada, por meio de concessões de serviços públicos, de construção de conservação de rodovias, ferrovias, aeroportos e portos.

Essa estrutura de gestão, embora salutar, ainda depende de melhor e eficiente governança, para se evitar os escândalos de corrupção, ativa e passiva, envolvendo políticos, agentes públicos da Administração direta e indireta e de entidades privadas nos procedimentos de licitações e de contratações públicas. Prova dessa afirmativa são os resultados da Operação Lava - Janto da Polícia Federal. A Accountability e a Compliance são indispensáveis meios de controle entre os demais, na governança corporativa e na governança pública.

\section{CONCLUSÕES}

As conclusões confirmam a larga repercussão jurídica do fenômeno da pobreza, descortinando-se a particular importância do Direito Administrativo para que, em obediência aos pontos de partida do sistema jurídico brasileiro, estabelecidos nos objetivos constitucionais da República, funcione como instrumento qualificado para o enfraquecimento dos denominados ciclos de pobreza, entre os quais se inclui o patrimonialismo nacional.

O patrimonialismo na Administração Pública tem forte estímulo no campo fértil da pobreza, contribuindo, em modelo de retroalimentação, para o incremento dos déficits comunitários, em quadro sistêmico de ofensas intermináveis aos direitos fundamentais.

O ideal normativo da Administração Pública eficiente se transforma, então, em simulacro, quando desconectado da governança e do planejamento, no Direito Administrativo.

A Administração Pública, portanto, obediente à leitura administrativa dos objetivos da República, deve, por meio da governança e do planejamento, participar, prioritariamente, da realização dos direitos fundamentais, contribuindo para a redução do hipertrófico simbolismo normativo brasileiro.

\section{REFERÊNCIA BIBLIOGRÁFICA}

ALMEIDA, Alberto Carlos. A cabeça do brasileiro. 4. ed. Rio de Janeiro: Record, 2007. 
BARACHO JÚNIOR, José Alfredo de Oliveira. Dimensões Paradoxais da Jurisdição Constitucional. In: CATTONI DE OLIVEIRA, Marcelo Andrade; MACHADO, Felipe Daniel Amorim. Constituição e processo: a contribuição do processo ao constitucionalismo democrático brasileiro. Belo Horizonte: Del Rey, 2009. 1ª Parte. Cap. 3, p. 153-167.

BARROSO, Luís Roberto. O Direito Constitucional e a Efetividade de suas Normas. 7. ed. Rio de Janeiro: Renovar, 2003.

BOLLE, Willi. Grandesertão.br: o romance da formação do Brasil. São Paulo: Duas Cidades; Editora 34, 2004.

BRASIL. Constituição da República Federativa do Brasil. Diário Oficial da União, 191-A, 05 out. 1988, p. 1. Disponível em:

<http://www.planalto.gov.br/ccivil_03/constituicao/ConstituicaoCompilado.htm>. Acesso em: 09 mar. 2018.

CAMPANTE, Rubens Goyatá. O patrimonialismo em Faoro e Weber e a sociologia brasileira. Dados, Rio de Janeiro, v. 46, n. 1, p. 153-193, 2003. Disponível em: $<$ http://www.scielo.br/scielo.php?script=sci_arttext\&pid=S0011-5258200 v. 6, p. 495-506, 2006.3000100005\&lng=en\&nrm=iso>. Acesso em: 19 mar. 2018.

CARVALHO, Luiz Maklouf. 1988: segredos da Constituinte. Os vinte meses que agitaram e mudaram o Brasil. Rio de Janeiro: Record, 2017.

COTRIM, Gilberto. Fundamentos da Filosofia. História e Grandes Temas. 15. ed. São Paulo: Saraiva, 2000.

COUTINHO, Marcos Pereira Anjo. A Administração Pública Democrática e o Controle pelo Ministério Público. De Jure - Revista Jurídica do Ministério Público do Estado de Minas Gerais, Belo Horizonte, n. 6, p. 495-506, jan./jun. 2006.

COUTINHO, Marcos Pereira Anjo. Ministério Público e o Enfrentamento dos Ciclos de Pobreza. In: MACÊDO, Marcus Paulo Queiroz; MARTELETO FILHO, Wagner (Orgs.). Temas avançados do Ministério Público. 2. ed. ampl. Salvador: Jus Podium, 2017.

Da MATTA, Roberto. O que faz o brasil, Brasil? 8. ed. Rio de Janeiro: Rocco, 1997.

FAORO, Raymundo. Os donos do poder: formação do patronato político brasileiro. 5. ed. São Paulo: Globo, 2012.

FERREIRA, Aurélio Buarque de Holanda. Dicionário Eletrônico Aurélio Século XXI. Rio de Janeiro: Nova Fronteira, Lexikon Informática, 1999. Versão 3.0. 1 CD-ROM.

FERREIRA, Carolina Iwancon. Governança Corporativa: nacional e internacional. Belo Horizonte: D’Plácido, 2014.

GARCIA, Emerson. Interpretação Constitucional: a resolução das conflitualidades intrínsecas da norma constitucional. São Paulo: Atlas, 2015.

KISSLER Leo; HEIDEMANN, Francisco G. Governança pública: novo modelo regulatório para as relações entre Estado, mercado e sociedade? Revista de Administração Pública, 
v. 40, n. 3, maio/jun. 2006. Disponível em: <http://www.scielo.br/scielo.php?script= sci_arttext\&pid=S0034-76122006000300008>. Acesso em: 8 abr. 2018.

LEAL, Victor Nunes [1914-1985]. Coronelismo, enxada e voto: o município e o regime representativo no Brasil. 7. ed. São Paulo: Companhia das Letras, 2014.

MCGLYNN, Hilary (Ed.). Poverty cycle. The Hutchinson Encyclopedia. 12. ed. Oxford: Helicon Publishing, 2002.

MICHAELIS. Dicionário brasileiro da língua portuguesa. São Paulo: Melhoramentos; A\&H Software Ltda., 2016. Edição eletrônica, versão 3.0.1.

NEMO, Philippe. La belle mort de l'athéisme moderne. Paris: Presses Universitaires de France - PUF, 2012.

NEVES, Marcelo. A constitucionalização simbólica. 3. ed. São Paulo: WMF Martins Fontes, 2011.

NOVAES, Adauto (Org.). A Crise da Razão. São Paulo: Companhia das Letras, 2006.

PAYNE, Ruby K. A framework for understanding poverty. 5th. Highlands: aha! Process, 2013.

PICK, Susan. Breaking the poverty cycle: the human basis for sustainable development. New York: Oxford University, 2010.

SCHWARTZMAN, Simon. As causas da pobreza. Rio de Janeiro: FGV, 2007.

SILVA, José Afonso da. Comentário Contextual à Constituição. 2. ed. São Paulo: Malheiros, 2006. 